\title{
Factors that influence utilization of the female condom among senior secondary school female students in urban Cameroon
}

\author{
Elvis Enowbeyang Tarkang, ${ }^{1,}$, Luchuo Engelbert Bain ${ }^{2}$ \\ ${ }^{1}$ HIV/AIDS Prevention Research Network, Cameroon, Opposite Premier Pharmacy, Commonwealth Avenue, Kumba, Cameroon \\ ${ }^{2}$ Department of Military Health, Ministry of Defence, Cameroon
}

Email address:

ebeyang1@yahoo.com (E. E. Tarkang)

\section{To cite this article:}

Elvis Enowbeyang Tarkang, Luchuo Engelbert Bain. Factors that Influence Utilization of the Female Condom among Senior Secondary School Female Students in Urban Cameroon. American Journal of Health Research. Vol. 2, No. 4, 2014, pp. 125-133.

doi: 10.11648/j.ajhr.20140204.14

\begin{abstract}
The female condom is a proven effective female controlled HIV prevention device. Sociocultural and biological factors predispose women to a heavier burden of HIV/AIDS than men. In Cameroon, with a high prevalence of HIV/AIDS, no study has investigated the factors influencing use of the female condom. This study was aimed to identify the factors influencing utilization of the female condom among senior secondary school female students in Kumba, Cameroon, using the Health Belief Model (HBM) as the framework. A cross-sectional correlational design was adopted using a stratified simple random sample of 398 senior secondary school female students to respond to a pretested selfadministered questionnaire. Data were analyzed using the Statistical Package for Social Sciences (SPSS) software version 20.0. Binomial logistic regression analyses were conducted at the 0.05 significance level. The proportion of the sexually active female students who reported ever used the female condom was very low, $8.0 \%$. None of the components of the HBM was statistically associated with female condom use in binomial logistic regression analysis. However, female students who disagreed that youths are prone to HIV; that a healthy looking person can be HIV positive (perceived susceptibility); that the consequences of having HIV/AIDS are so serious that they may want to avoid them (perceived severity); that correct and consistent use of the female condom can prevent HIV transmission (perceived benefit); that they feel confident that they can convince their partners to use the female condom during sexual intercourse (perceived selfefficacy) were associated with lower odds of using the female condom during sexual intercourse: OR $=0.44$; 0.94 ; 0.43 ; 0.59; and 0.60 respectively. Conversely, female students who disagreed that the female condom makes sexual intercourse less enjoyable; that due to religious beliefs they would feel guilty using the female condom; that they lack knowledge on the correct use of the female condom; and that distance to the nearest female condom supply point is far (perceived barriers) were associated with higher odds of using the female condom during sexual intercourse: OR=1.20; $1.57 ; 1.16$ and 1.49 respectively. Also, female students who perceived that they were at high risk of contracting HIV were at higher odds of using the female condom during sexual intercourse 1.87. Interventions to increase the perception of risk of contracting HIV among female students and strategies to empower them with female condom negotiation skills and to overcome tangible and psycho-social barriers to female condom use are highly needed.
\end{abstract}

Keywords: Female Condom Use, Health Belief Model (HBM), HIV/AIDS, Senior Secondary School Female Students, Urban Cameroon

\section{Introduction}

Appropriate and consistent use of condoms constitutes an integral component of HIV prevention. Physiologic susceptibility and gender inequalities are known drivers of relatively higher global HIV prevalence among girls and young women that are greater than among males of the same age [1]. Since the female condom was developed in 
the 1980s, studies have shown that providing it as part of a comprehensive prevention strategy results in increased levels of protection [2]. Coupled to the fact that its use is controlled by the woman and that it can be inserted several hours before intercourse, the female condom is estimated to be $94-97 \%$ effective in reducing the risk of HIV transmission if used correctly and consistently [2]. Despite the efficacy of the female condom in preventing HIV transmission, relatively low utilization rates are still reported, even in the developing countries [3, 4]. Inadequate knowledge and sociocultural barriers could partly explain this underuse [4-8].

The patterns and key determinants of female condom use, amongst secondary school and university students, could be of utmost importance for public health actors and health planners as regards to planning and execution of effective female condom related programs, especially in high prevalence settings like Cameroon.

In Cameroon, the Cameroon Association for Social Marketing, ACMS, is the main actor involved in the vulgarization and advocacy actions with regards to female condom use. There has been a massive increase in making female condoms available, and an accompanying 300\% decrease in its prices in the recent years. Availability of the female condom however has not been readily accepted by the youths. In a study amongst university students in Dschang in the West Region of Cameroon, $75.7 \%$ were aware of the existence and availability of the female condom. Although $97.8 \%$ of students considered the proper use of condoms as an effective HIV preventive tool, up to $34.5 \%$ of them fail to use condoms during sexual intercourses and $69 \%$ were not in favor of the use of female condom, mainly due to a decreasing sexual pleasure [9]. Overall HIV prevalence in Cameroon stands at 5.3\%, with females being more affected than males, with a prevalence of $6.5 \%$ [10]. The female condom coupled with other prevention interventions, if used consistently and appropriately could be a gateway in curbing the HIV associated morbidity and mortality in Cameroon.

Every HIV prevention programme is based on theories about how and why people change their behaviors. The Health Belief Model (HBM) was basically developed to address this issue. This paper uses the main components of the HBM, namely perceived susceptibility, perceived severity, perceived benefit, perceived barriers and perceived self-efficacy, as the theoretical framework to examine the factors that influence female condom use among female students in urban Cameroon.

The HBM is built on the premise that:

- a person will take a health-related action (female condom use) if he/she believes that a negative health condition (HIV) can be avoided

- a person will avoid a negative health condition (HIV) if he/she has a positive expectation of the recommended action (female condom use)

- a person will take a health-related action if he/she believes that he/she can successfully take the recommended health action (female condom use comfortably and with confidence) $[11,12]$

The prominent components of the HBM incorporate the following ideas:

- $\quad$ Perceived susceptibility, referring to an individual's beliefs about the chances of contracting a health condition

- $\quad$ Perceived severity, referring to one's beliefs of how serious a condition and its consequences are

- Perceived benefits, referring one's beliefs in the efficacy of the advised action to reduce the risk or seriousness of the impact of the health condition

- Perceived barriers, referring to one's beliefs in the tangible and psychological costs of the advised health action

- $\quad$ Perceived self-efficacy, referring to one's ability to successfully take the recommended health action $[11,12]$.

No study in Cameroon has investigated the factors influencing female condom use among female adolescents. In this study, we hypothesized in this study that female students who perceived themselves to be at high risk of contracting HIV, perceived the female condom to be effective in HIV/AIDS, perceived fewer barriers to using the female condom, perceived themselves susceptible to HIV transmission, perceived HIV/AIDS as a serious infection and believed in their ability to successfully use the female condom will be more likely to report having ever used them during sexual intercourse.

\section{Data and Methods}

\subsection{Study Design}

A cross-sectional design was adopted in this study, to investigate the factors that influence use of the female condom among high school female students in Kumba, Southwest region of Cameroon. The study was conducted in May 2014 in Kumba, the economic capital of the Southwest region of Cameroon, which happens to be the region ranked third in HIV/AIDS prevalence.

\subsection{Study Area}

Kumba is the administrative headquarters of Meme division, and the economic capital of the Southwest region, thus making it one of Cameroon's wealthiest urban centers, which together with the availability of economic and social amenities, industries and political institutions, has resulted in a high population density. With a total land area of 188.4 $\mathrm{Km}^{2}$, the total population of Kumba, a mixture of Christians and Muslims, was estimated at 166000 inhabitants (51.2\% males and $48.8 \%$ females) [13], the majority of whom are farmers and traders [14]. Administratively, the city is divided into three local government areas. 


\subsection{Study Population}

In this study, the accessible population included all the high school female students in Kumba, Cameroon, that portion of the target population to which the researcher had reasonable access [15]. The inclusion criteria were high school female students who were present and willing to participate in the study.

\subsection{Sampling Technique}

A stratified, simple random sampling technique was used to select the sample for this study. Probability sampling was used because it increased the likelihood that all the elements in the population would have an equal chance of being included in the sample [16]. The school attendance registers of the female students were used as the sampling frame to select a sample of 398 grade 10 to grade 12 (Form five to upper sixth) female students from three randomly selected high schools (one from each local government area) in Kumba, Cameroon. The students were stratified at the different levels of study, namely grade 10 (form 5), grade

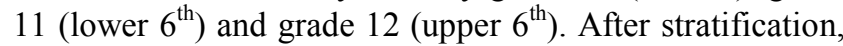
a proportional simple random sample was obtained by selecting students randomly from the sampling frame until the intended sample size was attained.

\subsection{Sample Size and Data Collection}

\subsubsection{Sample Size}

No data regarding awareness and knowledge about female condom use was available and thus the sample size was calculated using the formula for single population [17]. Thus the minimum sample size required for this study was 384; the final sample size was 398.

\subsubsection{Data Collection}

Data was collected by a self-administered anonymous questionnaire during a normal class period in May 2014. The questionnaire was pretested on a convenience sample of 20 high school female students who did not take part in the actual study, for clarity and to ascertain internal consistency. Respondents were given the self-administered questionnaires in English, which was their first language. The students were closely supervised by two trained female research assistants of the same age group as the respondents, while filling-in the questionnaires. The completed questionnaires were checked by the research assistants for errors and missing data before participants were allowed to go. Anonymously completed questionnaires were kept in a separate container from the signed informed consent forms in order to maintain anonymity.

\subsection{Data Management and Analysis}

Data were edited, cleaned, coded, entered and analyzed using the Statistical Package for Social Sciences (SPSS) version 20 software program. Data were summarized by means of descriptive statistics including the frequency table and analyzed using the binomial logistic regression.

\subsection{Informed Consent}

Informed consent was obtained after the potential participants and their parents/guardians (for those below 18 years) were informed of the study's objectives. Only students who gave consent to participate, were included in the study. All the parents/guardians (for participants below 18 years) were given the opportunity to withhold or withdraw their children from the study at any time they felt like.

\subsection{Ethical Approval}

Approval for this study was obtained from the HIV/AIDS Prevention Research Network, Cameroon (HIVPREC). Permission to conduct the study was sought from the research and ethics committee of the faculty of philosophy, religious and social studies of the Cameroon Christian University and the principals of the three participating high schools.

\subsection{Measures}

\subsubsection{Outcome (Dependent) Variable: Female Condom Use}

The outcome variable of interest for this study is having ever used the female condom during sexual intercourse as reported by the female students. The question asked respondents who were sexually active: "Have you ever used a female condom during sexual intercourse?" The response options were categorized into ' $1=$ yes' and ' $0=$ no'.

\subsubsection{Explanatory (Independent) Variables}

- $\quad$ Perceived susceptibility to HIV: This was measured with the questions, each considered separately: 'Youths are prone to HIV/AIDS,' and 'A healthy looking person can be HIV positive'. The response options were rated on a four-point Likert scale as ' $3=$ strongly agree', ' $2=$ agree', ' $1=$ disagree' and ' $0=$ strongly disagree'. 'Strongly disagree' and 'disagree' were coded as the index category.

- $\quad$ Perceived severity of HIV/AIDS: This measure was based on the degree of agreement with the following statement: 'The consequences of acquiring HIV are so serious that I may want to avoid them'. The response options were the same as for 'perceived susceptibility' and were coded in the same manner.

- $\quad$ Perceived benefit of female condom use: This measure was based on the degree of agreement with the following statement: 'Correct and consistent use of the female condom during sexual intercourse could prevent transmission of HIV'. The response options were the same as for 'perceived severity' and were coded in the same manner.

- $\quad$ Perceived female condom use self-efficacy: This measure was based on the degree of agreement with the following statement: 'I feel confident that I 
can convince my partner(s) to use the female condom during sexual intercourse'. The response options were the same as for 'perceived benefit' and were coded in the same manner.

- Perceived barriers to female condom use: This measure was based on the degree of agreement with the following statements: 'Female condom use decreases sexual pleasure,' 'I lack knowledge on the use of the female condom', 'Distance to the nearest female condom sales point is far', and 'Due to religious beliefs I feel guilty using the female condom'. The response options were the same as for 'perceived self-efficacy and were coded in same manner.

- Socio-Demographic Variables: The following socio-demographic variables were included in the study: age group, marital status, religious affiliation, and father's and mother's monthly incomes. Age was self-reported by respondents in years. Marital status was dichotomized as 'single' and 'married or cohabiting' (index category). Religious affiliation was dichotomized as 'Christian' and 'others' (index category). Father's and mother's monthly incomes were dichotomized as '200 000XAF and above' and 'less than 200 000XAF' (index category).

- Sexual Experience: This was measured with the question: Have you ever had sexual intercourse with a male partner? With ' $1=$ yes' or ' $0=$ no' as response options.

- Perception of risk of contracting HIV: This was measured with the following question: 'How at risk of contracting HIV are you?' The response options were ' $1=$ not at risk', ' $2=$ small risk', ' $3=$ moderate risk' and '4=high risk'.

\subsection{Method of Analysis}

Binomial logistic regression was performed using SPSS version 20 to examine the probability of having ever used the female condom during sexual intercourse. Binomial logistic regression predicts the probability that an observation falls into one of two categories of a dichotomous dependent variable based on one or more independent variables that can be either continuous or categorical.

For binomial logistic regression to be performed, the following assumptions must be met:

- The dependent variable should be measured on a dichotomous scale

- One or more independent variables which can be either continuous (interval or ratio variable) or categorical (ordinal or nominal)

- Independence of observations and the dependent variable should have mutually exclusive and exhaustive categories [18].

The procedure gives rise to estimates of odds of a certain event occurring (use of the female condom), given a set of explanatory variables (the components of the HBM).
All these assumptions were fulfilled in this study, thus justifying the use of binomial logistic regression to investigate the factors that influence use of the female condom among high school female students in Kumba, Cameroon.

To estimate the odds ratios (OR), all the components of the HBM and the socio-demographic variables were entered into the first model to evaluate possible interactions Significant interaction terms were retained and entered in a general model. The sequence of covariate removal from the model was determined by the likelihood ratio testing and the Hosmer-Lemeshow goodness-of-fit test to ensure that the covariate that contributed the least to the fit of the model would be removed first. Socio-demographic variables were retained in the final model as controls. The significant level for all statistical tests was $5 \%$.

To assess the relative importance of socio-demographic variables and the main components of the HBM, we built nine models predicting female condom use during sexual intercourse. These variables were entered into the model in a forward stepwise fashion to identify the net contribution of specific sets of variables while adjusting for the simultaneous effects of other sets of variables in the model. To assess the predictive utility of each component of the HBM as a whole model, that is how individuals with various combinations of health beliefs are more or less likely to have used the female condom during sexual intercourse, each component of the HBM was entered into the model one at a time.

\section{Results}

\subsection{Descriptive Statistics}

The response rate was $100 \%$. All the 398 respondents in this study were females, and the majority, $98.5 \%$ were between the ages of 15 and 24 years, with $95.0 \%$ being single. Three hundred and eighty four (96.5\%) were Christians. Majority of them, $60.5 \%$ indicated that their fathers' monthly incomes were less than 200 000XAF (US\$ 13.00 a day) and $75.6 \%$ indicated that their mothers' monthly incomes were less than 200 000XAF (US\$ 13.00 a day) (table 1). As for the components of the HBM, the perception that youths are prone to HIV and that a healthy looking person can be HIV positive (perceived susceptibility) were quite high, $79.4 \%$ and $86.4 \%$ respectively. Over $89 \%$ of the female students perceived that the consequences of having HIV/AIDS are so serious that they may want to avoid them (perceived severity). For perceived benefits, a considerable proportion of the students, $75.4 \%$ perceived that correct and consistent use of the female condom can prevent HIV transmission. Similarly, over $70.0 \%$ perceived that they can convince their partners to use the female condom during sexual intercourse (perceived self-efficacy). However, for perceived barriers, a considerable proportion of the students perceived that the female condom would make sex 
less enjoyable, $64.1 \%$; a slight majority, $52.3 \%$ perceived that due to religious beliefs they would feel guilty using the female condom; a considerable majority, $68.1 \%$ perceived that they lack knowledge on the correct use of the female condom and a slight majority, $52.5 \%$ perceived that the distance to the nearest female condom supply point is far (perceived barriers). The proportion of the sexually active female students who reported ever used the female condom is very low, $8.0 \%$.

Table 1. Descriptive statistics.

\begin{tabular}{|c|c|c|}
\hline Characteristic & Frequency & Percentage \\
\hline \multicolumn{3}{|l|}{ Age group $(\mathrm{n}=398)$} \\
\hline $13-14$ & 6 & 1.5 \\
\hline $15-24$ & 392 & 98.5 \\
\hline \multicolumn{3}{|c|}{ Marital status $(n=398)$} \\
\hline Single & 378 & 95.0 \\
\hline Others & 20 & 5.0 \\
\hline \multicolumn{3}{|c|}{ Religious Affiliation ( $\mathrm{n}=398)$} \\
\hline Christian & 384 & 96.5 \\
\hline Muslim & 14 & 3.5 \\
\hline \multicolumn{3}{|c|}{ Father's monthly income (in XAF) $(n=398)$} \\
\hline 200000 and above & 157 & 39.5 \\
\hline Less than 200000 & 241 & 60.5 \\
\hline \multicolumn{3}{|c|}{ Mother's monthly income (in XAF) ( $\mathrm{n}=398)$} \\
\hline 200000 and above & 97 & 24.4 \\
\hline Less than 200000 & 301 & 75.6 \\
\hline \multicolumn{3}{|c|}{ Perceived susceptibility to HIV/AIDS ( $\mathrm{n}=398$ ) } \\
\hline \multicolumn{3}{|c|}{ Youths are prone to HIV } \\
\hline Agree & 316 & 79.4 \\
\hline Disagree & 82 & 20.6 \\
\hline \multicolumn{3}{|c|}{ Perceived severity of HIV/AIDS ( $\mathrm{n}=398$ ) } \\
\hline \multicolumn{3}{|c|}{ The consequences of having HIVIAIDS are so serious that I may want to avoid them } \\
\hline Agree & 357 & 89.7 \\
\hline Disagree & 41 & 10.3 \\
\hline \multicolumn{3}{|c|}{ Perception of risk of contracting HIV $(n=398)$} \\
\hline \multicolumn{3}{|c|}{ How at risk of contracting HIV are you? } \\
\hline Not at risk & 146 & 36.7 \\
\hline Small risk & 85 & 21.4 \\
\hline Moderate risk & 41 & 10.3 \\
\hline High risk & 126 & 31.6 \\
\hline \multicolumn{3}{|c|}{ Perceived benefit of condom use $(\mathrm{n}=398)$} \\
\hline \multicolumn{3}{|c|}{ Correct and consistent female condom use can prevent HIV/AIDS } \\
\hline Agree & 300 & 75.4 \\
\hline Disagree & 98 & 24.6 \\
\hline \multicolumn{3}{|c|}{ Perceived barriers to condom use $(\mathrm{n}=398)$} \\
\hline \multicolumn{3}{|c|}{ Female condom use makes sex less enjoyable for either partner } \\
\hline Agree & 255 & 64.1 \\
\hline Disagree & 143 & 35.9 \\
\hline \multicolumn{3}{|c|}{ Due to religious beliefs I feel guilty using the female condom } \\
\hline Agree & 208 & 52.3 \\
\hline Disagree & 190 & 47.7 \\
\hline \multicolumn{3}{|c|}{ I lack knowledge on correct use of female condom } \\
\hline Agree & 271 & 68.1 \\
\hline Disagree & 127 & 31.9 \\
\hline \multicolumn{3}{|c|}{ Distance to the nearest female condom supply point is far } \\
\hline Agree & 209 & 52.5 \\
\hline Disagree & 189 & 47.5 \\
\hline \multicolumn{3}{|c|}{ Perceived condom use self-efficacy ( $\mathrm{n}=398$ ) } \\
\hline $\begin{array}{l}\text { I feel confident that } \\
\text { intercourse. }\end{array}$ & & \\
\hline Agree & 267 & 67.1 \\
\hline Disagree & 131 & 32.9 \\
\hline Sexual experience & & \\
\hline Have you ever hads & & \\
\hline Yes & 250 & 62.8 \\
\hline No & 148 & 37.2 \\
\hline Have you ever used & & \\
\hline Yes & 20 & 8.0 \\
\hline No & 230 & 92.0 \\
\hline
\end{tabular}




\subsection{Factors Influencing Female Condom Use}

Table 2 presents the summary and classification of the binomial logistic regression model. The model explained between $1-11 \%$ (Nagelkerke $\mathrm{R}^{2}$ ) of the variance in female condom use and correctly classified more than $91 \%$ of cases in the sample into female condom users and nonusers. The logistic regression models (Chi-square) were not statistically significant denoting inadequate explanatory power of the variables used in explaining the dependent variable.

Table 2. Model summary and classification.

\begin{tabular}{|c|c|c|c|c|c|c|c|}
\hline No & Model components & $\begin{array}{l}\text { Hosmer \& Lemeshow } \\
\text { Chi-square }\end{array}$ & df & $P$ values & Nagelkerke $\mathbf{R}^{2}$ & $\begin{array}{l}-2 \text { log } \\
\text { likelihood }\end{array}$ & $\begin{array}{l}\text { Percentage } \\
\text { correctly classified }\end{array}$ \\
\hline 1 & Perceived susceptibility to HIV/AIDS. & 0.683 & 2 & 0.711 & 0.013 & 137.632 & 91.9 \\
\hline 2 & Perceived severity of HIV/AIDS. & 0.000 & 0 & - & 0.016 & 137.306 & 91.9 \\
\hline 3 & Perceived Benefit of condom use. & 0.000 & 0 & - & 0.009 & 138.062 & 91.9 \\
\hline 4 & Perceived Barriers to condom use. & 9.481 & 8 & 0.303 & 0.017 & 137.201 & 91.9 \\
\hline 5 & Perceived condom use self-efficacy. & 0.000 & 0 & - & 0.010 & 137.940 & 91.9 \\
\hline 6 & Socio-Demographic variables. & 7.118 & 8 & 0.524 & 0.034 & 135.366 & 91.9 \\
\hline 7 & Perception of risk of contracting HIV & 0.000 & 2 & 1.000 & 0.028 & 136.064 & 91.9 \\
\hline 8 & All models & 4.253 & 8 & 0.834 & 0.102 & 127.963 & 91.9 \\
\hline 9 & All models except 6 & 9.492 & 8 & 0.302 & 0.092 & 129.100 & 91.9 \\
\hline
\end{tabular}

$\mathrm{df}=$ degree of freedom

Table 3. Odds Ratios (OR) of using the female condom from the logistic regression models.

\begin{tabular}{|c|c|c|c|c|}
\hline Effect & Odds Ratios (OR) & Confidence interval (CI) & Wald & Sig. \\
\hline \multicolumn{5}{|l|}{ Perceived Susceptibility } \\
\hline Youths are prone to HIV/AIDS & 0.44 & $(0.10-1.96)$ & 1.17 & 0.28 \\
\hline A healthy looking person can be HIV positive & 0.94 & $(0.26-3.39)$ & 0.01 & 0.92 \\
\hline \multicolumn{5}{|l|}{ Perceived severity } \\
\hline $\begin{array}{l}\text { The consequences of having HIV/AIDS are so serious that I may want to avoid } \\
\text { them }\end{array}$ & 0.43 & $(0.13-1.39)$ & 2.0 & 0.16 \\
\hline \multicolumn{5}{|l|}{ Perceived benefit of female condom use } \\
\hline $\begin{array}{l}\text { Correct and consistent use of the female condom can prevent the sexual } \\
\text { transmission of HIV }\end{array}$ & 0.59 & $(0.22-1.62)$ & 1.10 & 0.31 \\
\hline \multicolumn{5}{|l|}{ Perceived barriers to female condom use } \\
\hline Female condom use makes sex less enjoyable & 1.20 & $(0.45-3.15)$ & 0.01 & 0.73 \\
\hline Due to religious beliefs I would feel guilty using the female condom & 1.57 & $(0.61-4.10)$ & 0.87 & 0.35 \\
\hline I lack knowledge on correct use of the female condom & 1.16 & $(0.41-3.30)$ & 0.08 & 0.78 \\
\hline Distance to the nearest female condom supply point is far & 1.49 & $(0.53-4.20)$ & 0.56 & 0.46 \\
\hline \multicolumn{5}{|l|}{ Perceived condom use self-efficacy } \\
\hline $\begin{array}{l}\text { I feel confident that I can convince my partner(s) to use the female condom } \\
\text { during sexual intercourse }\end{array}$ & 0.60 & $(0.24-1.53)$ & 1.15 & 0.28 \\
\hline \multicolumn{5}{|l|}{ Perception of risk of contracting HIV } \\
\hline Small risk & 0.96 & $(0.32-2.87)$ & 0.01 & 0.94 \\
\hline Moderate risk & 0.36 & $(0.04-3.01)$ & 0.88 & 0.35 \\
\hline High risk & 1.87 & $(0.13-1.45)$ & 1.87 & 0.43 \\
\hline \multicolumn{5}{|l|}{ Socio-demographic variables } \\
\hline Age & 1.16 & $(0.71-1.90)$ & 0.36 & 0.55 \\
\hline Fathers' monthly incomes & 0.92 & $(0.60-1.42)$ & 0.13 & 0.72 \\
\hline Mothers' monthly incomes & 0.97 & $(0.59-1.60)$ & 0.02 & 0.90 \\
\hline
\end{tabular}

None of the components of the HBM was statistically associated with female condom use in binomial logistic regression analysis (table 3). However, female students who disagreed that youths are prone to HIV; that a healthy looking person can be HIV positive (perceived susceptibility); that the consequences of having HIV/AIDS are so serious that they may want to avoid them (perceived severity); that correct and consistent use of the female condom can prevent HIV transmission (perceived benefit); that they feel confident that they can convince their partners to use the female condom during sexual intercourse (perceived self-efficacy) were associated with lower odds of using the female condom during sexual intercourse: $\mathrm{OR}=0.44(95 \%$ CI $0.10-1.96) ; 0.94(95 \%$ CI $0.26-3.39) ; 0.43$ (95\% CI $0.13-1.39) ; 0.59$ (95\% CI $0.22-$ $1.62) ; 0.60$ (95\% CI $0.24-1.53)$ respectively.

Conversely, female students who disagreed that the female condom makes sexual intercourse less enjoyable; that due to religious beliefs they would feel guilty using the female condom; that they lack knowledge on the correct use of the female condom; and that distance to the nearest female condom supply point is far (perceived barriers) 
were associated with higher odds of using the female condom during sexual intercourse: $\mathrm{OR}=1.20$ (95\% CI 0.45 $3.15) ; 1.57$ (95\% CI 0.61-4.10); 1.16 (95\% CI 0.41-3.30) and 1.49 (96\% CI 0.53-4.20) respectively. Also, female students who perceived that they were at high risk of contracting HIV were at higher odds of using the female condom during sexual intercourse 1.87 (95\% CI 0.13-1.45).

\section{Discussion}

From the literature review it is evident that this study is the first, investigating the factors influencing use of the female condom among female students in Cameroon. In this study, we examined the factors associated with the use of the female condom among high school female students in an urban town of Cameroon using the Health Belief Model (HBM) as the framework.

Although majority of the female students perceived that youths are prone to HIV, 79.4\%; that a healthy looking person can be HIV positive, $86.4 \%$ (perceived susceptibility) and that the consequences of having HIV/AIDS are so serious that they may want to avoid them, $89.7 \%$ (perceived severity), only few perceived themselves to be at high risk of contracting HIV, $31.7 \%$. This lack of perception of risk of contracting HIV might be the reason for the lack of statistically significant associations between the components of the HBM and female condom use. This mismatch between students' knowledge and their practices (female condom use) is an important call for public health workers. A collaborative approach between public health workers and policy makers is needed to address this issue.

The Health Belief Model proposes that an individual will take a health preventive action if he/she regards him/herself as susceptible to a health condition (HIV/AIDS), believes that the recommended action available to him/her (female condom) would be beneficial in reducing his/her susceptible, if he/she believes that the anticipated barriers to taking the recommended action are outweighed by the benefits $[11,12]$.

The absence of statistically significant associations between the components of the HBM and female condom use is contrary to other studies by Meekers and Richter in Zimbabwe [19], who report perceived benefit of female condom use, perceived self-efficacy for female condom use and perception of risk of contracting HIV as significant predictors of female condom use; by Pandya et al among South American women [20], who report perceived barriers to female condom use as a significant factor influencing its use; by Napierala et al in Zimbabwe [21], who report perceived benefit of using the female condom as an important predictor of its use; by Choi et al [22], who report perceived self-efficacy for female condom use as a significant factor influencing its use; by Ezire et al in Nigeria[23], who report perceived barriers to female condom use as significant determinants of its use; and by Holmes et al [24] and Vijayakumar et al [2], who report socio-demographic factors as important predictors of female condom use. These discrepancies could be due to the fact that these studies were conducted on sex workers and in different religious settings compared to the current study. The fact that the female condom had been introduced these countries earlier than in Cameroon and the commitments of the various governments in these countries in promoting and distributing the female condom, may also explain these differences.

Based on the assumptions of the HBM, University of Twente, (2010) we concluded that without female students' perception of HIV being a threat, there could be no resultant preventative actions (using the female condom) against the disease. Therefore the perception of risk of contracting HIV is assumed to be the immediate antecedent of the use of the female condom to prevent HIV transmission. Therefore, the lack of significant associations between the components of the HBM and female condom use could be the result of low perception of risk of contracting HIV among the female students, which resulted in low use of the female condom during sexual intercourse.

The hypothesis that female students who perceived themselves to be at high risk of contracting HIV, perceived the female condom to be effective in HIV/AIDS, perceived fewer barriers to using the female condom, perceived themselves susceptible to HIV transmission, perceived HIV/AIDS as a serious infection and believed in their ability to successfully use the female condom will be more likely to report having ever used it during sexual intercourse was rejected based on our analyses. The associated confidence intervals were relatively wider, suggesting the need for a larger study.

Although there were no statistically significant associations between the HBM components and female condom use from the binomial logistic regression analysis (table 3), results from this study point to the need for interventions to increase the perception of risk of contracting HIV among female students and strategies to empower them with female condom negotiation skills. This study also suggests that AIDS prevention programmes in urban Cameroon should implement strategies to help female students to overcome tangible and psycho-social barriers to female condom use. It must be emphasized that with practice, the female condom becomes easier and more fun to use. These strategies should also include information on how to use the female condom correctly. The female condom can become a regular and pleasurable part of a romantic relationship. Furthermore, the government of Cameroon should consider subsidizing the female condom, to bring it within the financial reach of the young and poor female students, making them readily available in public health structures (hospitals and health centers).

\section{Limitations}

Possible biases might have affected the results of this study. Firstly, all measures were self-reported. Thus responses may have been subject to recall bias intentional 
misreporting of perceptions and condom use behavior, through giving socially acceptable responses. However, the assurance of anonymity and confidentiality around the study should have minimized possible misreporting. Secondly, the reported lower frequency of female condom use may have caused even significant findings to be subject to high variability due to large confidence intervals. The findings of this study should therefore be generalized with caution. A deeper insight could in obtained if the study could be repeated with a larger sample size. Thirdly, since this study was conducted in an urban area, the results cannot be generalized to the rural setting and to out-ofschool youth mostly with low level of education and with different environmental characteristics. Fourthly, the study was done in a predominantly Christian environment. Results could differ in Muslim settings.

\section{Conclusion}

Female condom use among female students in urban Cameroon is low and was not statistically associated with the components of the HBM. However, female students who disagreed that youths are prone to HIV; that a healthy looking person can be HIV positive (perceived susceptibility); that the consequences of having HIV/AIDS are so serious that they may want to avoid them (perceived severity); that correct and consistent use of the female condom can prevent HIV transmission (perceived benefit); that they feel confident that they can convince their partners to use the female condom during sexual intercourse (perceived self-efficacy) were associated with lower odds of using the female condom during sexual intercourse. Conversely, female students who disagreed that the female condom makes sexual intercourse less enjoyable; that due to religious beliefs they would feel guilty using the female condom; that they lack knowledge on the correct use of the female condom; and that distance to the nearest female condom supply point is far were associated with higher odds of using the female condom during sexual intercourse. Also, female students who perceived that they were at high risk of contracting HIV were at higher odds of using the female condom during sexual intercourse.

Although no statistically significant associations were observed between the constructs of the HBM and the desire or ability to use the female condom, the female condom remains an integral component of the HIV prevention package to be considered for the prevention of HIV infection among female adolescents in urban Cameroon. Promotional strategies and training activities designed to increase the awareness and willingness to use the device should be strengthened.

\section{Authors' Contributions}

EET designed the study, directed the field work, performed the statistical analysis and drafted the manuscript. BEL helped to draft the manuscript. Both authors read and approved the final manuscript.

\section{Competing Interests}

The authors declare that they have no competing interests.

\section{References}

[1] UNAIDS, Global Report on the global HIV epidemic, Geneva, Switzerland, 2013.

[2] G. Vijayakumar, Z. Mabude, J. Smit, and M. Beksinska, Lurie, A review of female-condom effectiveness: patterns of use and impact on protected sex acts and STI incidence, Int J STD AIDS, vol. 17(10), pp. 652-9, 2006.

[3] C. El Bcheraoui, M. Y. Sutton, F. P. Hardnett, and S. B. Jones, Patterns of condom use among students at historically Black colleges and universities: implications for HIV prevention efforts among college-age young adults, AIDS Care, vol. 25(2), pp. 186-93, 2013.

[4] F. M. Guerra, and L. C. Simbayi, Prevalence of knowledge and use of the female condom in South Africa, vol. 18(1), pp. 146-58, 2014.

[5] D. Mehra, P. O. Östergren, B. Ekman, and A. Agardh, Inconsistent condom use among Ugandan university students from a gender perspective: a cross-sectional study, Glob Health Action, vol. 7, pp. 229-42, 2014.

[6] I. Teva, M. P. Bermudez, M. T. Ramiro, and T. RamiroSanchez, Analysis of sexual behavior in adolescents, Curr HIV Res, vol. 11(7), pp. 512-9, 2013.

[7] T. Kavinya, Have Malawian women embraced the female condom? Malawi Med J, vol. 25(3), pp. 95, 2013.

[8] J. Lammers, S. J. van Wijnbergen, and D. Willebrands, Condom use, risk perception, and HIV knowledge: a comparison across sexes in Nigeria, HIV AIDS (Auckl), vol. 21(5), pp. 283-93, 2013.

[9] M. Sobze Sanou, J. Fokam, R. Guetiya Wadoum, G. Russo, J. F. Onohiol, D. B. Djeunang, P. P. Nkamedjie, N. F. Zambou, Y. Zefack, A. Galletta, M. Arduini, E. Franca, A. Panà, and V. Colizzi, Condom perception and prevention of HIV/AIDS infection in Cameroon: appraisal of knowledge, attitudes and practices among level one students of the University of Dschang, Ig Sanita Pubbl, vol. 69(2), pp. 183-94, 2013.

[10] UNAIDS, 2010 Report on the Global AIDS Epidemic, Geneva, Switzerland, UNAIDS, 2010.

[11] L. K. Bartholomew, G. Parcel, G. Kok, and N. H. Gottlieb, Behavior oriented theories used in health promotion. In J. Allegrante., \& K. McLeroy (eds). Planning Health Promotion Programs, 81-135. San Francisco: Jossey-Bass, 2006.

[12] University of Twente, Health Belief Model. Unpublished online information, Netherlands. From http://www.utwente.nl/cw/theorieenovericht/Theory\%20clu sters/Health (Accessed on 12/11/2011), 2010.

[13] Bureau Central des Recensements et des etudes de Population (BCREP), Livre "Rapport de Presentation, Cameroon, 2010. 
[14] Kumba Urban Council (KUC), Kumba Urban Council Statistical Year Book, Buea. The National Printing Press, 2000 .

[15] N. Burns, and S. K. Grove, The practice of nursing research: conduct, critique and utilization; $5^{\text {th }}$ edition. St Louis, ELSEVIER, 2005.

[16] H. I. Brink, C. Van der Walt, and G. Van Rensburg, Fundamentals of research methodology for health care professionals, $2^{\text {nd }}$ edition. Cape Town, Juta, 2006.

[17] S. L. Levy, and S. Lemeshow, Sampling of populations: Methods and applications, third edition. New York, John Wiley \& Sons, 1999.

[18] A. Agresti, An Introduction to categorical Data Analysis, New York, Wiley, 2007.

[19] D. Meekers, and K. Richter, Factors associated with use of the female condom in Zimbabwe, International Family Planning Perspectives, vol. 31(1), pp. 30-37, 2005.

[20] N. Pandya, U. A. Siddiqi, and S. A. R. Naqvi, Prevalence and predictors of female condom use amongst South American Women, The Health, vol. 2(2), pp. 41-44, 2011.

[21] S. Napierala, M. S. Kang, T. Chipato, N. Padian, and A. Van der Straten, Female condom uptake and acceptability in Zimbabwe, AIDS Educ Prev, vo 1. 20, pp. 121-134, 2008.

[22] K. H. Choi, C. Hoff, S. E. Gregorich, O. Grinstead, C. Gomez, and W. Hussey, The Efficacy of the Female Condom Skills Training in HIV Risk Reduction among Women: a Randomized Controlled Trial, Am J Public Health, vol. 98(10), pp. 1841-8, 2008.

[23] O. Eziro, O. Oluigbo, V. Archibong, O. Ifeanyi, and J. Anyanti, Barriers to repeated use of female condom among women and men of reproductive age in Nigeria, Journal of AIDS and HIV Research, vol. 5(6), pp. 206-213, 2013.

[24] L. Holmes Jr., G. O. Ogungbade, D. D. Ward, O. Garri-Son, R. J. Peters, S. C. Kalichman, J. Lahai-Momohe, and E. J. Essien, Potential markers of female condom use among inner city African-American Women, AIDS Care, vol. 20(4), pp. 470-7, 2008. 